\title{
Are Canadian urology residency programs fulfilling the Royal College expectations?: A survey of graduated chief residents
}

\author{
Bassel G. Bachir, MD; Armen G. Aprikian, MD, FRCSC; Wassim Kassouf, MD, FRCSC \\ Department of Surgery (Urology), McGill University, Montreal, QC
}

See related article on page 116.

Cite as: Can Urol Assoc J 2014;8(3-4):109-15. http://dx.doi.org/10.5489/cuaj.1339

Published online April 14, 2014.

\section{Abstract}

Introduction: We assess outgoing Canadian urology chief residents' well-being, their satisfaction with their surgical training, and their proficiency in surgical procedures throughout their residency program.

Methods: In 2012 an anonymous survey was sent by email to all 29 graduated urology chief residents across Canada. The survey included a list of all urologic surgical procedures listed by the Royal College of Physicians and Surgeons of Canada (RCPSC). According to the $A / B / C$ classification used to assess competence in these procedures (A most competent, C least competent), we asked chief residents to self-classify their competence with regards to each procedure and we compared the final results to the current RCPSC classification.

Results: The overall response rate among chief residents surveyed was $97 \%$. An overwhelming majority $(96.4 \%)$ of residents agreed that the residency program has affected their overall well-being, as well as their relationships with their families and/or partners $(67.8 \%)$. Overall, $85.7 \%$ agreed that research was an integral part of the residency program and $78.6 \%$ have enrolled in a fellowship program post-graduation. Respondents believed that they have received the least adequate training in robotic surgery $(89.3 \%)$, followed by female urology $(67.8 \%)$, andrology/sexual medicine/ infertility (67.8\%), and reconstructive urology (61.4\%). Interestingly, in several of the 42 surgical procedures classified as category $A$ by the RCPSC, a significant percentage of residents felt that their proficiency was not category A, including repair of urinary fistulae $(82.1 \%)$, pediatric indirect hernia repair and meatal repair for glanular hypospadias (67.9\%), open pyeloplasty $(64.3 \%)$, anterior pelvic exenteration (61.6\%), open varicocelectomy $(60.7 \%)$ and radical cystoprostatectomy (33.3\%). Furthermore, all respondents $(100 \%)$ believed they were deficient in at least 1 of the 42 category A procedures, while $53.6 \%$ believed they were deficient in at least 10 of the 42 procedures.
Conclusions: Most residents agree that their residency program has affected their overall well-being as well as their relationships with their families and/or partners. There is also a clear deficiency in what outgoing residents perceive they have achieved and what the RCPSC mandates. Future work should concentrate on addressing this discrepancy to assure that training and RCPSC expectations are better aligned.

\section{Introduction}

Graduating residents inevitably form part of the growing pool of active physicians tasked with taking care of a growing and aging population. It is therefore imperative that these residents are educated in a manner consistent with guidelines established by the Royal College of Physicians and Surgeons of Canada (RCPSC), to ensure that national health standards of care are maintained. Moreover, it is these same graduating physicians that provide the most accurate feedback on the efficacy of contemporary and novel models of medical and surgical training that they themselves have experienced. This is particularly true in urology, where the evolution of surgical practice to incorporate laparoscopic, and more recently robotic surgery, has revolutionized training curricula nationwide.

To assess outgoing Canadian urology chief residents' well-being, their satisfaction with different aspects of surgical training and their proficiency in various surgical procedures throughout their residency program, we conducted a survey of all outgoing urology chief residents across Canada in 2012.

\section{Methods}

An anonymous email survey was sent to all 29 graduated urology chief residents from all provinces across Canada at the end of July 2012 (1 month after graduation). We gathered basic demographic information, including age, gender and 
relationship status; a 5-point Likert scale was employed for most survey questions. The first part of the survey included questions pertaining to well-being, as well as questions on clinical fellows and adequacy of training in the different subspecialties of urology, including pediatric urology, urologic oncology, reconstructive urology, female urology, laparoscopic surgery, robotic surgery, endourology, genitourinary trauma, infertility/sexual medicine/andrology and transplant surgery. The second part of the survey listed 95 different urologic surgical procedures, including all urologic surgical procedures listed by the RCPSC. According to the A/B/C classification used to assess competence in these procedures (A mandatory competence, C least competent, Appendix 1), we asked chief residents to self-classify their competence with regards to each procedure and we compared the final results to the current RCPSC classification.

\section{Results}

\section{Baseline demographics}

The overall response rate amongst chief residents surveyed was $97 \%$. The median age of graduated residents in 2012 was 31 years (range: $27-36)$. Most (71.4\%) of graduates were male. Most of the residents were either from Quebec $(42.9 \%)$ or Ontario $(35.7 \%)$. Only $28.6 \%$ were single; the remaining respondents were in a relationship. An overwhelming majority $(96.4 \%)$ of residents agreed that the residency program has affected their overall well-being, as well as their relationships with their families and/or partners $(67.8 \%)$. More than half had debt levels of over $\$ 50,000$, with only $17.9 \%$ having debt levels of less than $\$ 10,000$. Finally, $71.4 \%$ participated in a urology preparatory review course prior to their RCPSC exams, and all were on a study leave with mean duration of $36 \pm 17$ days prior to the exams (Table 1).

\section{Attitudes towards research and fellows}

Overall, $85.7 \%$ agreed that research was an integral part of the residency program and most $(78.6 \%)$ reported to be joining a fellowship program. Only $39.3 \%$ would like to practice urology in the community setting.

When questioned about the presence of a clinical fellow, $64 \%$ agreed that fellows add to the educational experience of the resident; however, only $4 \%$ believed that fellows teach surgical skills better than the attending staff. Interestingly, $34.6 \%$ agreed that fellows are a burden and take cases away from residents, and $26.9 \%$ claim that they had too many fellows in their division. Only 3.8\% thought that certain cases, such as robotic cases, should be performed only by the fellow. While most $(61.6 \%)$ agreed that fellows should

\begin{tabular}{|c|c|}
\hline & No. respondents (\%) \\
\hline \multicolumn{2}{|l|}{ Age } \\
\hline$\leq 30$ years & $11(39.3)$ \\
\hline$>30$ years & $17(60.7)$ \\
\hline \multicolumn{2}{|l|}{ Gender } \\
\hline Male & $20(71.4)$ \\
\hline Female & $8(28.6)$ \\
\hline \multicolumn{2}{|l|}{ Province } \\
\hline Quebec & 12 (42.9) \\
\hline Ontario & $10(35.7)$ \\
\hline British Columbia & $3(10.7)$ \\
\hline Nova Scotia & $2(7.1)$ \\
\hline Manitoba & $1(3.6)$ \\
\hline \multicolumn{2}{|l|}{ Relationship status } \\
\hline Married & $16(57.1)$ \\
\hline Single & $8(28.6)$ \\
\hline Common-law partnership & $4(14.3)$ \\
\hline Divorced & $0(0)$ \\
\hline \multicolumn{2}{|l|}{ No. children/dependents } \\
\hline 3 & $2(7.1)$ \\
\hline 1 & $5(17.9)$ \\
\hline 0 & $21(75)$ \\
\hline \multicolumn{2}{|l|}{ Debt level } \\
\hline$<\$ 10,000$ & $5(17.9)$ \\
\hline$\$ 10,000-\$ 25,000$ & $3(10.7)$ \\
\hline$\$ 25,000-\$ 50,000$ & $5(17.9)$ \\
\hline$>\$ 50,000$ & $15(53.6)$ \\
\hline \multicolumn{2}{|l|}{ Robotic surgery training } \\
\hline Yes & $16(57.1)$ \\
\hline No & 12 (42.9) \\
\hline \multicolumn{2}{|l|}{ Graduates per year } \\
\hline 3 or less & $19(67.9)$ \\
\hline More than 3 & $9(32.1)$ \\
\hline \multicolumn{2}{|l|}{ Joining fellowship } \\
\hline Yes & $22(78.6)$ \\
\hline No & $6(21.4)$ \\
\hline \multicolumn{2}{|l|}{ Review course } \\
\hline Yes & $20(71.4)$ \\
\hline No & $8(28.6)$ \\
\hline
\end{tabular}

take call, only $34.6 \%$ stated that fellows should participate in morning rounds along with residents.

\section{Education and surgical proficiency}

Most (89.3\%) agreed that surgical simulators and animal labs add to the value of the teaching experience and improve surgical skills. Respondents also believed that they have received the least adequate training in robotic surgery $(89.3 \%)$, followed by female urology $(67.8 \%)$, andrology/ sexual medicine/infertility (67.8\%), and reconstructive urology $(61.4 \%)$. Conversely, they reported to have received the best training in endourology (92.9\%) and urologic oncology $(92.9 \%)$, followed by pediatric urology $(75 \%)$, transplant surgery (67.9\%) and laparoscopy (60.7\%). Interestingly, in several of the 42 surgical procedures classified as category 
A by the RCPSC, a significant percentage of residents felt that their proficiency was not category $\mathrm{A}$; the procedures included repair of urinary fistulae $(82.1 \%)$, pediatric indirect hernia repair and meatal repair for glanular hypospadias $(67.9 \%)$, open pyeloplasty (64.3\%), anterior pelvic exenteration $(61.6 \%)$, open varicocelectomy $(60.7 \%)$ and radical cystoprostatectomy (33.3\%) (Table 2 ). Importantly, all of the respondents $(100 \%)$ believed they were deficient in at least 1 of the 42 category A procedures, while $53.6 \%$ believed they were deficient in at least 10 procedures of the 42 .

\section{Resident perspective on RCPSC classifications}

When residents were questioned about what procedure belongs in which RCPSC category, they listed several category B and C procedures as category A. These procedures included transrectal ultrasound guided biopsy of prostate $(78.6 \%)$, open drainage of perinephric, perivesical and retroperitoneal abscess (71.4\%), endopyelotomy $(71.4 \%)$, partial penectomy $(67.9 \%)$, insertion of testicular prosthesis $(59.3 \%)$, simple retropubic prostatectomy $(57.1 \%)$ and transurethral incision of external sphincter (57.1\%) (Table 3). In contrast, respondents thought that some category A procedures should be listed as B or C (Table 4). Furthermore, several procedures not yet listed by the RCPSC were also classified by residents, including holmium laser or GreenLight transurethral resection of the prostate $(7.4 \% \mathrm{~A}, 70.4 \% \mathrm{~B}$, $22.2 \% \mathrm{C})$, robotic prostatectomy $(7.4 \% \mathrm{~A}, 33.3 \% \mathrm{~B}, 59.3 \%$ C), laparoscopic partial nephrectomy $(21.4 \%$ A, $67.9 \%$ B, $10.7 \% \mathrm{C})$, robotic partial nephrectomy $(3.6 \% \mathrm{~A}, 35.7 \% \mathrm{~B}$, $60.7 \% \mathrm{C})$, and laparoscopic or robotic pelvic lymphadenectomy $(14.3 \%$ A, $42.9 \%$ B, $42.9 \% \mathrm{C})$.

\section{Discussion}

Most residents agree that their residency program has affected their overall well-being, as well as their relationships with their families and/or partners. There is also a clear deficiency in what outgoing residents achieve and what the RCPSC expects, as evidenced by more than half the graduated residents being deficient in at least $25 \%$ of category A procedures.

Compared to two previous surveys conducted by Preston and colleagues on urology chief residents in Canada in 2007 and $2008,{ }^{1}$ our study shows that the capacity at residency programs has not increased over the past 5 years; there is an almost identical number of graduating residents in 2012 compared to 2007 and $2008(n=28)$. Furthermore, as in previous years, most of the graduating residents were from programs in Ontario or Quebec. However, unlike in earlier years, there was a considerably higher number of female graduating residents $(28.6 \%$ in 2012 vs. $17.9 \%$ in 2007 and $3.6 \%$ in 2008), although this is still less than the percentage
Table 2. List of category A procedures and residents perceived proficiency

Procedure My proficiency (\%)

Open varicocelectomy

Radical inguinal orchiectomy

Orchidopexy for inguinal testis

Testicular biopsy

Fulguration of venereal warts

Repair of testicular torsion

Vasectomy

Hydrocelectomy

Cavernosal shunting procedures for priapism

Biopsy of penile lesions

Circumcision

Cystoscopy, retrograde pyelography, insertion of ureteral stent

Ureteroscopy, lithotripsy and basket extraction of ureteric calculi

Endoscopic injection for vesico-ureteric reflux Cystolitholopaxy

Transurethral resection of bladder tumours

Transurethral resection/incision of ureterocele

Transurethral biopsy of bladder and urethra

Transurethral resection of prostate

Radical cystoprostatectomy (in male)

Anterior pelvic exenteration (in female)

Open pelvic lymphadenectomy

lleal conduit diversion

Open prostatectomy

Open nephroureterectomy

Laparoscopic nephroureterectomy

Open partial nephrectomy

Open radical nephrectomy

Laparoscopic radical nephrectomy

Percutaneous nephrolithotomy

Open pyeloplasty

Repair of traumatic intraperitoneal bladder rupture

Percutaneous suprapubic catheter insertion

Open suprapubic cystostomy

Open uretero-ureterostomy

Open uretero-neocystostomy

Pediatric indirect hernia repair

Meatal repair for glanular hypospadias

Urethral meatotomy, meatoplasty

Repair of urinary fistulae - involving

bladder, urethra, ureter, kidney

Procedures for correction of stress urinary incontinence

Urethral dilatation and visual internal

urethrotomy

\begin{tabular}{|c|c|c|}
\hline A & B & C \\
\hline 39.3 & 46.4 & 14.3 \\
\hline 100 & 0 & 0 \\
\hline 60.7 & 39.3 & 0 \\
\hline 50 & 42.9 & 7.1 \\
\hline 61.5 & 34.6 & 3.8 \\
\hline 100 & 0 & 0 \\
\hline 71.4 & 25 & 3.6 \\
\hline 100 & 0 & 0 \\
\hline 53.6 & 14.3 & 32.1 \\
\hline 82.1 & 14.3 & 3.6 \\
\hline 100 & 0 & 0 \\
\hline 100 & 0 & 0 \\
\hline 100 & 0 & 0 \\
\hline 48.1 & 48.1 & 3.7 \\
\hline 100 & 0 & 0 \\
\hline 100 & 0 & 0 \\
\hline 51.9 & 29.6 & 18.5 \\
\hline 100 & 0 & 0 \\
\hline 100 & 0 & 0 \\
\hline 66.7 & 29.6 & 3.7 \\
\hline 38.4 & 53.8 & 7.7 \\
\hline 92.9 & 3.6 & 3.6 \\
\hline 74.1 & 22.2 & 3.7 \\
\hline 85.2 & 14.8 & 0 \\
\hline 64.3 & 32.1 & 3.6 \\
\hline 67.9 & 38.6 & 3.6 \\
\hline 75 & 25 & 0 \\
\hline 89.3 & 10.7 & 0 \\
\hline 85.7 & 14.3 & 0 \\
\hline 78.6 & 21.4 & 0 \\
\hline 35.7 & 57.1 & 7.1 \\
\hline 88.9 & 11.1 & 0 \\
\hline 96.3 & 3.7 & 0 \\
\hline 74.1 & 22.2 & 3.7 \\
\hline 71.4 & 25 & 3.6 \\
\hline 85.7 & 14.3 & 0 \\
\hline 32.1 & 35.7 & 32.1 \\
\hline 32.1 & 42.9 & 25 \\
\hline 82.1 & 17.9 & 0 \\
\hline 17.9 & 67.9 & 14.3 \\
\hline 75 & 21.4 & 3.6 \\
\hline 100 & 0 & 0 \\
\hline
\end{tabular}


Bachir et al.

\section{Table 3. List of Category B and C procedures with residents' classification}

Laparoscopic varicocelectomy (C)

Microscopic epididymo-vasostomy (C)

Vasovasostomy (B)

Insertion of testicular prosthesis (B)

Laparoscopic orchiopexy/orchiectomy for abdominal testis (B)

Correction of mid and distal shaft hypospadias (B)

Correction of proximal hypospadias and epispadias (C)

Correction of penile curvature (B)

Partial penectomy (B)

Total or radical penectomy $(\mathrm{B})$

Insertion of penile prosthesis (B)

Simple retropubic prostatectomy (B)

Transrectal ultrasound guided biopsy of the prostate (B)

Laparoscopic prostatectomy (C)

Percutaneous nephrostomy/obtaining access for percutaneous nephrolithotomy (B)

Anatrophic nephrolithotomy (C)

Open nephrolithotomy (B)

Procedures for renal trauma repair (B)

Open renal biopsy (B)

Open radical nephrectomy with vena cava thrombectomy below diaphragm (B)

Removal of vena caval and atrial tumour thrombus for carcinoma of kidney (C)

Laparoscopic pyeloplasty (B)

Extra-corporeal shock wave lithotripsy (B)

Cadaveric and live donor renal harvesting for transplantation (B)

Renal transplantation (C)

Laparoscopic live donor nephrectomy (C)

Transplant (graft) nephrectomy (C)

Open adrenalectomy (B)

Laparoscopic adrenalectomy (B)

Orthotopic neobladder (e.g., Studer) (B)

Continent cutaneous diversions (e.g., Indiana Pouch) (B)

Open trans-uretero-ureterostomy (B)

Open ureterolysis (B)

Surgical reconstruction for exstrophy $(C)$

Augmentation cystoplasty (B)

Vesicostomy (B)

Primary nerve-sparing retroperitoneal lymph node dissection (B)

Post-chemotherapy retroperitoneal lymph node dissection (C)

Inguinal lymphadenectomy for penile cancer (B)

Insertion of artificial urinary sphincter (B)

Transurethral incision of external sphincter (C)

Endopyelotomy (B)

Perineal urethrostomy (B)

Urethrectomy (B)

Cutaneous ureterostomy/pyelostomy (B)

Urethral reconstruction for anterior urethral strictures and pelvic fracture distraction injuries (C)

Resection of posterior urethral valves (B)

Open drainage of perinephric, perivesical and retroperitoneal abscess (B)

should be (\%)

\begin{tabular}{|c|c|c|}
\hline A & B & C \\
\hline 10.7 & 25 & 64.3 \\
\hline 0 & 25.9 & 74.1 \\
\hline 7.1 & 42.9 & 50 \\
\hline 59.3 & 22.2 & 18.5 \\
\hline 37 & 40.7 & 22.2 \\
\hline 10.7 & 50 & 39.3 \\
\hline 0 & 53.3 & 46.7 \\
\hline 33.3 & 59.3 & 7.4 \\
\hline 67.9 & 32.1 & 0 \\
\hline 28.6 & 39.3 & 32.1 \\
\hline 17.9 & 39.3 & 42.9 \\
\hline 57.1 & 35.7 & 7.1 \\
\hline 78.6 & 17.9 & 3.6 \\
\hline 7.4 & 25.9 & 66.7 \\
\hline 39.3 & 53.6 & 7.1 \\
\hline 3.6 & 32.1 & 64.3 \\
\hline 7.1 & 25 & 67.9 \\
\hline 50 & 39.3 & 10.7 \\
\hline 25.9 & 51.9 & 22.2 \\
\hline 10.7 & 60.7 & 28.6 \\
\hline 3.6 & 14.3 & 82.1 \\
\hline 42.9 & 50 & 7.1 \\
\hline 53.6 & 32.1 & 14.3 \\
\hline 14.3 & 46.4 & 39.3 \\
\hline 14.3 & 53.6 & 32.1 \\
\hline 21.4 & 42.9 & 35.7 \\
\hline 17.9 & 28.6 & 53.6 \\
\hline 39.3 & 42.9 & 17.9 \\
\hline 50 & 32.1 & 17.9 \\
\hline 14.3 & 57.1 & 28.6 \\
\hline 7.1 & 42.9 & 50 \\
\hline 10.7 & 50 & 39.3 \\
\hline 51.9 & 44.4 & 3.7 \\
\hline 0 & 7.4 & 92.6 \\
\hline 29.6 & 59.3 & 11.1 \\
\hline 33.3 & 59.3 & 7.4 \\
\hline 11.1 & 55.6 & 33.3 \\
\hline 0 & 29.6 & 70.4 \\
\hline 25.9 & 48.1 & 25.9 \\
\hline 14.8 & 55.6 & 29.6 \\
\hline 57.1 & 28.6 & 14.3 \\
\hline 71.4 & 28.6 & 0 \\
\hline 50 & 42.9 & 7.1 \\
\hline 12 & 56 & 32 \\
\hline 10.7 & 39.3 & 50 \\
\hline 3.6 & 46.4 & 50 \\
\hline 42.9 & 42.9 & 14.3 \\
\hline 71.4 & 17.9 & 10.7 \\
\hline
\end{tabular}




\begin{tabular}{|c|c|c|c|}
\hline \multirow[t]{2}{*}{ Procedure } & \multicolumn{3}{|c|}{ What I think Royal College classification should be (\%) } \\
\hline & A & B & C \\
\hline Open varicocelectomy & 39.3 & 46.4 & 14.3 \\
\hline Radical inguinal orchiectomy & 100 & 0 & 0 \\
\hline Orchidopexy for inguinal testis & 75 & 25 & 0 \\
\hline Testicular biopsy & 64.3 & 25 & 10.7 \\
\hline Fulguration of venereal warts & 88.5 & 7.7 & 3.8 \\
\hline Repair of testicular torsion & 100 & 0 & 0 \\
\hline Vasectomy & 92.9 & 3.6 & 3.6 \\
\hline Hydrocelectomy & 100 & 0 & 0 \\
\hline Cavernosal shunting procedures for priapism & 60.7 & 21.4 & 17.9 \\
\hline Biopsy of penile lesions & 92.9 & 3.6 & 3.6 \\
\hline Circumcision & 100 & 0 & 0 \\
\hline Cystoscopy, retrograde pyelography, insertion of ureteral stent & 100 & 0 & 0 \\
\hline Ureteroscopy, lithotripsy and basket extraction of ureteric calculi & 100 & 0 & 0 \\
\hline Endoscopic injection for vesico-ureteric reflux & 51.9 & 37 & 11.1 \\
\hline Cystolitholopaxy & 100 & 0 & 0 \\
\hline Transurethral resection of bladder tumours & 100 & 0 & 0 \\
\hline Transurethral resection/incision of ureterocele & 53.6 & 35.7 & 10.7 \\
\hline Transurethral biopsy of bladder and urethra & 100 & 0 & 0 \\
\hline Transurethral resection of prostate & 100 & 0 & 0 \\
\hline Radical cystoprostatectomy (in male) & 70.4 & 25.9 & 3.7 \\
\hline Anterior pelvic exenteration (in female) & 57.7 & 38.5 & 3.8 \\
\hline Open Pelvic lymphadenectomy & 89.3 & 7.1 & 3.6 \\
\hline Ileal conduit diversion & 70.4 & 29.6 & 0 \\
\hline Open prostatectomy & 88.9 & 11.1 & 0 \\
\hline Open nephroureterectomy & 75 & 25 & 0 \\
\hline Laparoscopic nephroureterectomy & 67.9 & 21.4 & 10.7 \\
\hline Open partial nephrectomy & 82.1 & 17.9 & 0 \\
\hline Open radical nephrectomy & 96.4 & 3.6 & 0 \\
\hline Laparoscopic radical nephrectomy & 89.3 & 10.7 & 0 \\
\hline Percutaneous nephrolithotomy & 78.6 & 21.4 & 0 \\
\hline Open pyeloplasty & 50 & 42.9 & 7.1 \\
\hline Repair of traumatic intraperitoneal bladder rupture & 100 & 0 & 0 \\
\hline Percutaneous suprapubic catheter insertion & 92.6 & 7.4 & 0 \\
\hline Open suprapubic cystostomy & 85.2 & 14.8 & 0 \\
\hline Open uretero-ureterostomy & 75 & 21.4 & 3.6 \\
\hline Open uretero-neocystostomy & 92.9 & 7.1 & 0 \\
\hline Pediatric indirect hernia repair & 21.4 & 57.1 & 21.4 \\
\hline Meatal repair for glanular hypospadias & 46.4 & 35.7 & 17.9 \\
\hline Urethral meatotomy, meatoplasty & 89.3 & 10.7 & 0 \\
\hline Repair of urinary fistulae - involving bladder, urethra, ureter, kidney & 32.1 & 57.1 & 10.7 \\
\hline Procedures for correction of stress urinary incontinence & 85.7 & 14.3 & 0 \\
\hline Urethral dilatation and visual internal urethrotomy & 100 & 0 & 0 \\
\hline
\end{tabular}

of female residents at other surgical programs across Canada. The number of female residents in general surgery programs has recently been reported as high as $38 \% .^{2}$ The prevalence of, and exposure to, robotic surgery is also increasing, with $57.1 \%$ of residents surveyed involved in a residency program that included robotic surgery training, compared to $35.7 \%$ in $2008 .^{2}$ In addition, $78.6 \%$ of residents surveyed claimed to be joining a fellowship program; this is rather high, but similar to rates in other studies of $70 \%$ to $90 \% .^{3,4}$ In fact, a recent analysis by Welk and colleagues revealed that $72 \%$ of all graduated Canadian urology residents between 1998 and $2009(n=258)$ completed a fellowship. ${ }^{5}$

The impact of fellowship training and clinical fellows on resident education in Canadian urology programs was first 
assessed by Grober and colleagues in $2008 .^{6}$ In their singlecentre study, they found significant differences in opinion between residents, fellows and faculty regarding the impact of the clinical fellow on resident education. Interestingly, our results revealed that urology residents' views of clinical fellows have not changed over the past few years; most agreed that fellows add to the educational experience of the resident and most disagreed that certain cases should be performed only by fellows.

There is no doubt that residency training in urology has evolved significantly over the last 3 decades to incorporate numerous novel training methods including animal labs, and virtual reality laparoscopic and robotic simulators. These tools help to introduce residents to innovative technologies and to teach them advanced surgical techniques without the added risk of operating on real patients. Furthermore, several studies have confirmed the transferability of skills acquired on simulators to the actual clinical setting. ${ }^{7}$ It is therefore not surprising to find that most residents surveyed agreed that surgical simulators and animal labs add to the value of the teaching experience and improve surgical skills. In addition, the importance of surgical simulators may extend beyond the task of teaching residents surgical skills. Given the considerable variability in assessment tools for evaluating and examining resident technical skills, simulators may potentially and eventually be used throughout academic institutions as standardized surgical assessment tools.

Of interest, most urology residents agreed that the residency program has affected their overall well-being; they tended to sleep less, workout less and eat poorly. In addition, most respondents believed that the residency program has negatively affected their relationships with their families and/or partners. These findings are consistent with a recent survey by Aminazadeh and colleagues examining stress in Canadian surgical residencies, where $87 \%$ of residents reported having had a stressful to extremely stressful past year; residents identified working hours, time pressure, lack of sleep and call frequency as the most common stressors. ${ }^{8}$

Recent American studies have highlighted the fact that graduating urology residents may not be adequately experienced in several surgical procedures, including urinary diversions and retroperitoneal lymphadenectomy. ${ }^{9,10}$ One of the reasons explaining this lack of training is the absence of standardized tools to assess residents' surgical and technical competence throughout their residency, much like the yearly in-service exam assesses theoretical knowledge. In the presence of these tests, deficiencies in surgical competence may be identified during training, thereby possibly allowing for further training in deficient procedures. In our study, respondents believed that they have received the least adequate training in robotic surgery. This is not surprising, given that only about half the residents surveyed were in a residency program that included robotic training and that robotic training is currently not a RCPSC objective. A recent analysis by Mamut and colleagues looked at Canadian urology resident exposure to minimally invasive surgery (MIS) and open surgeries. The authors found a statistically significant increase in the number of MIS cases coupled with a statistically significant decrease in open cases that residents were exposed to in the 2008-2009 year compared to the 2003-2004 academic year. ${ }^{11}$ If these trends continue, future residents will certainly be exposed to more MIS and robotic cases, at the expense of less open surgery exposure.

The RCPSC classifies surgical procedures into 3 categories $(\mathrm{A} / \mathrm{B} / \mathrm{C})$ based on competence. Graduated residents are expected to be able to individually and independently perform all category A procedures. Category A surgical procedures are defined as: "The fully trained resident must be competent to individually perform the following procedures, in addition to being able to manage the patient prior to, during, and after the procedure."12 In our study, $100 \%$ of respondents believed they were deficient in at least 1 of the 42 category A procedures, while more than half believed they were deficient in at least 10 . As such, our results revealed a wide and concerning discrepancy in what the RCPSC expects, and what urology residents achieve based on their own selfassessment. In addition, it would be very interesting and important for future such studies to survey the corresponding teaching faculty of graduating residents with respect to surgical competence. This survey may help in the iterative process of revising RCPSC objectives. However, it must be stressed that no definitive conclusions on the adequacy of training objectives can be derived based on what 1 year of graduates perceives, but rather an assessment over several years is warranted. Furthermore, and unfortunately, neither the graduates nor their teachers possess validated and trusted measurements of competence. Nevertheless, if a significant proportion of graduating residents believe that they are not competent in level A procedures, it is crucial that this information be taken into consideration when addressing any schism between RCPSC guidelines and resident surgical competence. Lastly, as Canadian residency training moves towards a competency-based model, the biggest challenge for educators and trainees alike will be to come up with a real validated measure of resident competence.

While several solutions may be proposed, it is quite a challenge to be able to fully address this discrepancy. Firstly, the introduction of standardized tools to assess technical skills may help to identify and subsequently rectify deficiencies early during the residency program. In addition, more emphasis should be placed on rotations where residents have higher exposure to category A procedures, although this may be difficult because category A procedures encompass a wide spectrum of urologic surgeries. Furthermore, it is important to note that the RCPSC does not actually mandate the objectives of training. This task is performed 
by a peer group of urologists comprised of past and current Canadian urology residency program directors. This Royal College Specialty Committee in Urology meets regularly, and annually revises training objectives based on regional and national practice patterns, technology utilization and expert opinion. With expert opinion occupying the lowest tiers in the levels of evidence-based medicine, there remains room for improvement in this tedious process. It is imperative that the various surgical procedures listed by the RCPSC undergo continuous updating and possible reclassification to better reflect contemporary training and practices. For example, in our study, several category B and C procedures were in fact categorized as $\mathrm{A}$ by most residents and vice versa. Also, transrectal ultrasound and prostatic biopsy are listed by the RCPSC as category B; however, $79 \%$ of the respondents thought it should be a category A procedure. Perhaps some current category A procedures should be reclassified.

Our study is limited by the fact that it captures the resident experience of only the most recent graduating class. However, the strengths of our study include the very high response rate and the fact that our results truly capture a nationwide self-assessment of graduated residents. Furthermore, we were able to identify several deficiencies in resident training that deserve increased attention.

\section{Conclusions}

Most residents agree that their residency program has affected their overall well-being, as well as their relationships with their families and/or partners. There is also a clear deficiency in what outgoing residents perceive they achieved in surgical competence and what the RCPSC expects. Future work should concentrate on addressing this discrepancy to assure that actual training and RCPSC expectations are better aligned.

Acknowledgement: Dr. Wassim Kassouf is a recipient of a Research Scholar Award from the FRSQ (Fonds de recherche du Québec - Santé).

Competing interests: Dr. Bachir declares no competing financial or personal interests. Dr. Aprikian is a board observer for Bioniche Inc., a member of the Speakers bureau for Amgen, Abbvie and Astellas. He has also received grants from Amgen, Astellas and Abbvie. Moreover, he has participated in a clinical trial within the past 2 years for Astellas. Dr. Kassouf is an Advisory Board member and a speaker for Amgen and Astellas. He has also received grants and honoraria from these companies. He is currently participating in unpaid clinical trials.

\section{References}

1. Preston MA, Blew BD, Breau RH, et al. Survey of senior resident training in urologic laparoscopy, robotics and endourology surgery in Canada. Can Urol Assoc J 2010;4:42-6. http://dx.doi.org/10.5489/ cuaj.09036

2. Tomlinson C, Labossiere J, Rommens K, et al. The Canadian general surgery resident: defining current challenges for surgical leadership. Can I Surg 2012;55:S184-90.

3. Freilich DA, Nguyen HT, Phillips JL. Factors influencing residents' pursuit of urology fellowships. Urology 2011;78:986-92. http://dx.doi.org/10.1016/j.urology.2011.05.068

4. Yang G, Villalta JD, Weiss DA, et al. Gender differences in academic productivity and academic career choice among urology residents. J Urol 2012;188:1286-90. http://dx.doi.org/10.1016/i.juro.2012.06.022

5. Welk B, Kodama R, Macneily A. The newly graduated Canadian urologist: Over-trained and underemployed? Can Urol Assoc J 2013;7:E10-5. http://dx.doi.org/10.5489/cuaj.12095

6. Grober ED, Elterman DS, Jewett MA. Fellow or foe: The impact of fellowship training programs on the education of Canadian urology residents. Can Urol Assoc J 2008;2:33-7.

7. Larsen $C R$, Oestergaard J, Ottesen $B S$, et al. The efficacy of virtual reality simulation training in laparoscopy: a systematic review of randomized trials. Acta Obstet Gynecol Scand 2012;91:1015-28. http://dx.doi. org/10.1111/j.1600-0412.2012.01482.x

8. Aminazadeh N, Farrokhyar F, Naeeni A, et al. Is Canadian surgical residency training stressful? Can J Surg 2012;55:S145-51.

9. Chang SS, Smith JA Jr, Herrell SD, et al. Assessing urinary diversion experience in urologic residency programs: Are we adequately training the next generation? J Urol 2006;176:691-3. http://dx.doi. org/10.1016/i.juro.2006.03.096

10. Lowrance WT, Cookson MS, Clark PE, et al. Assessing retroperitoneal lymphadenectomy experience in United States urological residency programs. J Urol 2007;178:500-3; discussion 503. Epub 2007 Jun 11. http://dx.doi.org/10.1016/i.juro.2007.03.139

11. Mamut AE, Afshar K, Mickelson JJ, et al. Surgical case volume in Canadian urology residency: A comparison of trends in open and minimally invasive surgical experience. J Endourol 201 1;25:1063-7. http://dx.doi. org/10.1089/end.2010.0304

12. Royal College of Physicians and Surgeons of Canada website. www.royalcollege.ca. Accessed March 19, 2014.

Correspondence: Dr. Wassim Kassouf, Division of Urology, McGill University Health Centre, 1650 Cedar Ave., Rm L8-315, Montreal, QC H3G 1A4; fax: 514-934-8297; wassim.kassouf@muhc.mcgill.ca

\begin{tabular}{l} 
Appendix 1 \\
\hline The Royal College of Physicians and Surgeons of Canada \\
classifies surgical procedures into 3 categories: A, B and C. Below \\
is a definition of these 3 categories. \\
\hline Category A: The fully trained resident must be competent to \\
individually perform the following procedures, in addition to \\
being able to manage the patient prior to, during, and after the \\
procedure. \\
Category B: The fully trained resident will know how to do the \\
following procedures, including indications, and perioperative \\
management. The resident may not have actually done one of \\
these procedures independently during the residency training \\
period. \\
\hline Category C: The fully trained resident will be able to describe the \\
following procedures, the indications for these procedures, and \\
the perioperative complications that might be encountered. \\
\hline
\end{tabular}

